\title{
Influence of traffic calming measures on drivers' behaviour
}

\author{
Robert Ziolkowski \\ Bialystok University of Technology, Wiejska 45E str., 15-351 Bialystok, Poland
}

\begin{abstract}
Road users' safety comes out from imperfections of a human-vehicle-road system. Previous research and analyses have proved that the key factor in this system in scope of traffic safety is human factor however it is being emphasized that more attention should be given to road geometry and its surroundings. In many situations existing streets' geometry regardless of the city area enables drivers to speed and excessive speed is pointed as a key factor in road traffic crashes and injuries in both rural and urban areas. Hence it is of great importance to effectively manage speed and enforce speed limits on existing road network and/or within areas demanding special care. Traffic calming measures (TCM) when applied appropriately can be extremely effective method of speed management but their influence on drivers' behaviour is very different and depending on the type of measure can cause hazardous reaction.

The aim of this paper is to analyse impacts of traffic calming measures on drivers' behaviour. Research area was located in city of Bialystok, Poland and included a group of commonly applied measures such as: speed humps, speed cushion, speed cameras, raised median island, raised pedestrian crossings and raised intersection. Measurements of instantaneous speed, acceleration, deceleration and route tracking data were undertaken to develop the investigation.
\end{abstract}

Keywords: Traffic safety; traffic calming measures; speed profiles.

\section{Introduction}

At present, an estimated 1.24 million people die each year and between 20 and 50 million suffer non-fatal road injuries [1]. Moreover it is estimated that by 2020 road traffic crashes will have moved from ninth to third in the world disease burden ranking, as measured in disability adjusted life years, and to second in developing countries. Traffic safety reports from many countries show that speed and speeding is at the core of the road safety problem and is a causation factor in around one third of fatal accidents. It affects not only the risk of being involved in an accident but also and the injury consequences of an accident. It is more difficult to properly react in time and prevent an accident at a higher speed. Excess and inappropriate speed is very common not only on rural roads but also in built-up areas [2]. Although the frequency of speed limit violations depends on many different aspects ie. local speed limit, characteristics of the roads and its environment or traffic conditions it is still very common. The investigations results from city of Bialystok proved that in free flow conditions the number or drivers exceeding the speed limit varies from 50 up to $100 \%$ [3-5]. Additionally speed has also serious consequences on the environment and energy consumption. Hence emerges the need for implementation of efficient and effective speed management tools. Speed management is defined as a set of measures to limit the negative effects of excessive and inappropriate speeds and aims to reduce the incidence of driving too fast for the prevailing conditions, and to maximize compliance with speed limits. Thus speed management, defined as a range of measures aimed at balancing safety and efficiency of vehicle speed on a road network, is believed to be a successful way of safety improvement and should be implemented widely and wisely [6-8]. Traffic calming being a part of speed management involves altering of motorist behavior on a street or on a street network along with other legal, planning or physical modification to a road layout in order to improve environmental quality, safety for vulnerable road users and reduce accident numbers and severity by lowering speeds. Traffic calming can be considered in four levels:

- local/spot traffic restraint;

- corridor traffic restraint;

- wide-area restraint;

- suppression of traffic demand at the urban or large-scale level.

Corresponding author: Robert Ziolkowski. E-mail address: robert.ziolkowski@pb.edu.pl

http://dx.doi.org/10.3846/enviro.2014.180

(C) 2014 The Authors. Published by VGTU Press. This is an open-access article distributed under the terms of the Creative Commons Attribution License, which permits unrestricted use, distribution, and reproduction in any medium, provided the original author and source are credited. 


\section{Types of Traffic calming Measures}

Traffic calming schemes incorporate a wide range of measures intended to both speed reduction and environmental terms although their effectiveness vary according to the measures employed. Specific measures can be grouped into four categories [9], [10]:

- vertical deflection (road hump, bump, lump and table, cushion, rumble strip, raised pedestrian crossings and intersection);

- horizontal deflection (curb-extension, chicane, gateway, raised median island, traffic circle);

- physical obstruction (semi and diagonal diverter, right-in and righ-out island, raised median through intersection, street closure);

- signs and pavement markings.

Within spot traffic restraints from among a number of currently available devices vertical shifts placed in the carriageway are the most effective in speed reduction but their effectiveness is reduced to a very short section hence particular attention should be given to their location. Due to constraints relating their usage those measures are very common mainly in residential streets in places where particular caution should be given because of children presence or unprotected road users casualties occurrence.

Area-wide traffic calming schemes are also typically implemented in residential areas in order to reduce the environmental and safety problems caused by road traffic. Through traffic is than removed from residential streets by implementing street closures or one-way systems or by establishing road streets hierarchy. Main roads generally does not involve the use of vertical shifts and are improved in order to carry a larger traffic volume without additional delays or more accidents while on residential streets various speed reducing measures are installed. Those solutions reduce a number of traffic accidents more effectively in residential streets than on main roads.

In developing countries it is very common that, mainly due to costs, traffic calming measures operate separately instead of systematic solutions. Hence their effectiveness is limited to a short distances and is believed to cause only disturbance in traffic flow and smoothness. When applied inappropriately in a series and distances between devices are too short or too long then they can push drivers to aggressive driving style. Frequent deceleration and acceleration maneuvers may lead to additional dangerous behavior due to lack of speed uniformity.

\section{Methodology and data collection}

The general methodology includes measurements and driver behavior estimates through in-field measurements. Driver behavior can be characterized by key speed parameters and driving technique expressed by acceleration and deceleration maneuvers. To compare changes in driver behavior as a results of traffic calming measures presence, both before and after driving data is required. However if such data is not available the comparison is possible by comparing free sections with calmed ones which are similar in geometry and traffic conditions. The in-field evaluations have been conducted analyzing a percentage of speeding drivers as well as average speed and spot speed. The data were collected by utilizing portable radar speed detector and wireless GPS data logger. Radar detector was employed to record instantaneous speed in the streets with administrative speed limits while GPS data logger allowed to monitor and record second-by-second in-field vehicle position along the tested sections. The GPS data logger provides longitude data to an accuracy of $3 \mathrm{~m}$, altitude data to an accuracy of $3 \mathrm{~m}$ an speed measurements to an accuracy of $0,1 \mathrm{~m} / \mathrm{s}$. The device is widely configurable and after switching on collects data automatically.

The vehicle speed and position was collected in $1 \mathrm{~s}$ interval and the travel data including instantaneous speed was collected during peak-off hours in order to ensure free flow driving and to avoid the interactions with other vehicles or pedestrians. The accelerations and decelerations were calculated based on the successive second-by-second speed records. The test vehicle was a passenger car and the drivers were suggested to drive according to their natural driving patterns. As a result a number of at least 20 runs for each section was achieved.

\section{Objectives and site specific}

The aim of the research was to evaluate drivers behavior in free of restraints conditions and in vicinity of different traffic calming measures using speed profiles and driving characteristics expressed by average spot speed, decelerations and acceleration and to analyse the TCMs' impact on mean speed.

In Bialystok area 18 streets were selected for detailed study. Six of them had no specific traffic calming measures installed while the other had TCMs implemented. The first six streets were selected, including different geometric characteristics, in order to evaluate drivers behavior regarding geometry characteristics and existing administrative limits:

- Dolistowska - administrative speed limit of $40 \mathrm{~km} / \mathrm{h}$ (single carriageway);

- Chełmonskiego - administrative speed limit of $50 \mathrm{~km} / \mathrm{h}$ (single carriageway);

- Slawinskiego - administrative speed limit of $50 \mathrm{~km} / \mathrm{h}$ (single carriageway);

- Piastowska - administrative speed limit of $50 \mathrm{~km} / \mathrm{h}$ (dual carriageway);

- Branickiego - administrative speed limit of $50 \mathrm{~km} / \mathrm{h}$ (dual carriageway);

- 1000-lecia - administrative speed limit of $70 \mathrm{~km} / \mathrm{h}$ (dual carriageway). 
Streets with TCMs solutions included speed humps, speed cushion, speed cameras, raised median island, raised pedestrian crossings and raised intersection:

- Tuwima (raised intersection);

- Pulaskiego (raised pedestrian crossings);

- Kruczkowskiego (flat top bupm);

- Wschodnia (series of speed bumps);

- Brzechwy (speed cushions);

- Pogodna (raised median island);

- Mickiewicza (raised median island, speed camera and parking positions located along the street);

- Jana Pawla II, Pilsudskiego, Branickiego, Slawinskiego (speed camera).

\section{Results and analysis}

The summary characteristics of the driving sections together with the key speed characteristics are presented in Table 1. The first stage of the analysis concerning drivers' behaviour under free flow conditions provided has proved that speeding is very common in Bialystok. In the streets with no traffic calming measures installed regardless street function or geometric characteristics the percentage of drivers exceed existing administrative speed limits varied from $73 \%$ to $100 \%$. The highest percentage of speeding drivers was recorded on Dolistowska street - a single carriageway residential street with posted speed limit of $40 \mathrm{~km} / \mathrm{h}$. Another disadvantageous found at this stage of analyses was high heterogeneity of instantaneous speed occurring in these streets and presented as speed histograms in Fig. 1. This can be particularly dangerous in situations requiring violent maneuvers.

Table 1. Street and speed parameter characteristics

\begin{tabular}{|c|c|c|c|c|c|c|c|c|c|}
\hline Street & $\begin{array}{l}\text { Type of } \\
\text { cross } \\
\text { section }\end{array}$ & $\begin{array}{l}\text { Mean } \\
\text { speed } \\
{[\mathrm{km} / \mathrm{h}]}\end{array}$ & $\begin{array}{l}\text { Standard } \\
\text { deviation }\end{array}$ & $\mathrm{V}_{85}$ & $\mathrm{~V}_{15}$ & $\mathrm{~V}_{85}-\mathrm{V}_{15}$ & $\begin{array}{l}\mathrm{V}_{\mathrm{psl}} \\
{[\%]}\end{array}$ & $\begin{array}{l}\text { Posted speed limit/ } \\
\text { calming measure }\end{array}$ & Type of street \\
\hline Dolistowska & $1 / 2$ & 62.3 & 11.04 & 65.8 & 48.9 & 16.9 & 100 & $40 \mathrm{~km} / \mathrm{h}$ & residential street \\
\hline Chełmońskiego & $1 / 2$ & 56.8 & 8.22 & 62.6 & 43.6 & 19 & 73 & $50 \mathrm{~km} / \mathrm{h}$ & residential street \\
\hline Sławinskiego & $1 / 4$ & 60.9 & 7.98 & 66.5 & 50.1 & 16.4 & 87 & $50 \mathrm{~km} / \mathrm{h}$ & collector street \\
\hline Piastowska & $2 / 2$ & 64.2 & 9.36 & 72.6 & 51.2 & 21.4 & 94 & $50 \mathrm{~km} / \mathrm{h}$ & arterial street \\
\hline Branickiego & $2 / 2$ & 57.1 & 7.25 & 60.8 & 45.7 & 15.1 & 81 & $50 \mathrm{~km} / \mathrm{h}$ & arterial street \\
\hline 1000-lecia & $2 / 2$ & 80.2 & 11.41 & 85.5 & 64.4 & 21.1 & 79 & $70 \mathrm{~km} / \mathrm{h}$ & suburban arterial \\
\hline Tuwima & $1 / 2$ & 19.4 & 1.53 & 19.5 & 15.3 & 4.2 & & raised junction & residential street \\
\hline Pułaskiego & $1 / 2$ & 21.8 & 3.85 & 28.4 & 19.4 & 9 & & raised pedestrian crossing & collector street \\
\hline Wschodnia & $1 / 2$ & 21.1 & 3.88 & 23.5 & 16.6 & 6.9 & & rounded speed bumps & residential street \\
\hline Kruczkowskiego & $1 / 2$ & 17.7 & 3.05 & 21.7 & 14.6 & 7.1 & & flat speed bumps & residential street \\
\hline Kruczkowskiego & $1 / 2$ & 20.0 & 3.14 & 22.2 & 15.6 & 6.6 & & rounded speed bumps & residential street \\
\hline Brzechwy & $1 / 2$ & 29.1 & 9.8 & 38.5 & 16.4 & 22.1 & & speed cushion & residential street \\
\hline Pogodna & $1 / 2$ & 58.3 & 8.96 & 63.7 & 46.5 & 17.2 & 81 & raised median island & collector street \\
\hline Mickiewicza & $1 / 2$ & 43.7 & 6.64 & 47.1 & 32.5 & 14.6 & 64 & $\begin{array}{l}\text { raised median island } \\
\text { and speed camera }\end{array}$ & collector street \\
\hline Jana Pawla II & $2 / 2$ & 72.8 & 12.17 & 78.7 & 58.3 & 20.4 & 50 & speed camera & arterial street \\
\hline Pilsudskiego & $2 / 3$ & 52.4 & 8.04 & 57.4 & 42.6 & 14.8 & 58 & speed camera & arterial street \\
\hline Branickiego & $2 / 2$ & 61.0 & 7.35 & 66.8 & 50.3 & 16.5 & 94 & speed camera & arterial street \\
\hline Slawinskiego & $1 / 4$ & 50.1 & 7.98 & 56.8 & 39.5 & 17.3 & 93 & speed camera * & arterial street \\
\hline
\end{tabular}

* posted speed limit $-40 \mathrm{~km} / \mathrm{h}$

$\mathrm{V}_{\mathrm{psl}}-\%$ of drivers exceeding posted speed limit

$\mathrm{P}_{\text {Vdop }}[\%]-$ percentage of speeding drivers; $\mathrm{V}_{\mathrm{av}}$ - average speed; $\mathrm{V}_{85,15}-85$ th and 15 th percentile. 

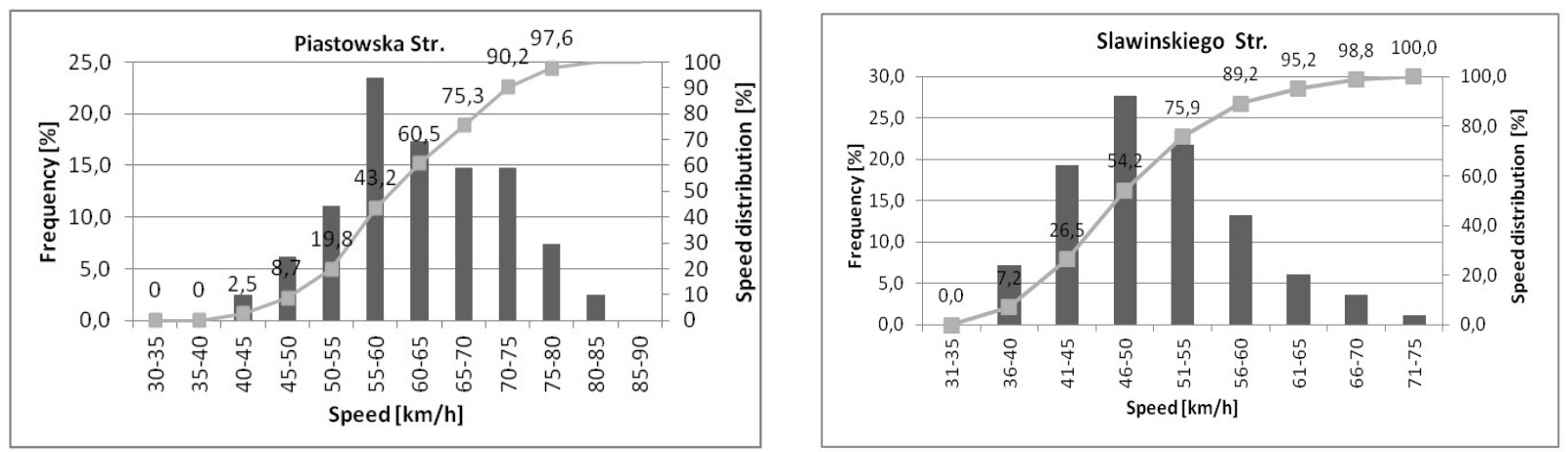

Fig. 1. Histograms of instantaneous vehicle speed on streets with administrative speed limits

A great number of speeding drivers makes it necessary and important to introduce effective way of speed management. Since administrative speed limits are not very powerful one of the most widely used in Bialystok are traffic calming measures but their effectiveness is also questionable. Average speed at places of physical obstructions varied from $17.7 \mathrm{~km} / \mathrm{h}$ (flat top bump) to $29.1 \mathrm{~km} / \mathrm{h}$ (speed cushion) while the average speed around speed cameras was between $50.1 \mathrm{~km} / \mathrm{h}$ and $72.8 \mathrm{~km} / \mathrm{h}$ and is distinctly relevant to administrative speed limit - the higher limit exists the higher average speed is recorded. It seems, based on the results presented in Table 1, that geometrical features of the speed bump do not have an impact on the average instantaneous speed and the differences in speed values are low and do not exceed $8 \%$.

The presence of raised median island if installed separately will have no expected effect on drivers behaviour. This was the case with a median island in Pogodna street. The percentage of recorded speeding drivers is comparable to the average speed on other streets without such obstructions. The reason for that can be fact that width of driving lines left for passing cars after raised island installation was too excessive and did not enforce drivers to slowing down. The most desirable drivers behaviour has been found on Mickiewicza street where instantaneous speed has remained at low level of variations along the whole tested section. This can be explained by the presence of coupled effects of speed camera, raised median island and parking places situated along the tested section. Results provided in Table 1 confirm that soft nondestructive solutions of TCMs like speed cameras and administrative speed limits have a very low impact on drivers behaviour and are not effective. The effectiveness can be only pointed either for physical or combined physical and administrative measures. However their effectiveness still remains diverse and considering the reduction of instantaneous speed values most effective are vertical deflections but on the other hand, despite high efficiency, their use is limited to residential streets in which operating speed remains at relatively lower levels. Considering speed characteristic in range of its uniformity, expressed as a difference between 85th and 15th percentile speed, it is visible that around nondestructive measures recorded speed values present wider range when compared to the speeds in vicinity of other TCMs.

Figures 2-5 present mean speed profiles along tested sections to present disturbances arising from the presence of traffic calming devices. As it could be expected the speed decreased and reached its minimum values at the device locations and then again increased. This feature is useful in determining the influence zone of each measure which can be described as the spatial range in which speed remains at decreased level and hence the longer region is the more effective measure is. From the graphs shown it emerges that the type of traffic calming devices influence driver technique and sharpness of deceleration and acceleration maneuvers.

Analysing changes of deceleration and acceleration phenomenon around individual traffic calming measures some essential differences can be observed. While driving a street with speed cameras or speed cushion two areas of different deceleration dynamics can be extracted. First stage of deceleration is mild and starts at a greater distance from the location of traffic calming measure while the second stage is much severe and starts at the distance of about $100 \mathrm{~m}$ from the TCM's location in case of the speed camera presence and about $70 \mathrm{~m}$ in case of the speed cushions location. In other cases single and more uniform deceleration process before a threshold can be distinguished and is followed by acceleration up to the point of stabilized speed. For a series of speed bumps and raised intersection the braking process starts from 60 to 80 meters before the slow point while the range of raised pedestrian crossings impact is even shorter and varies from 45 to $55 \mathrm{~m}$. The results given in Table 2 shows that slow points set in a series lead to more aggressive driving. The values of deceleration recorded before speed bumps (Wschodnia) and raised pedestrian crossings (Pulaskiego) are much higher (from $43 \%$ to $211 \%$ ) than for single installations.

In order to calculate values of decelerations and accelerations occurring as a result of specific TCMs presence individual speed profiles were examined. Figure $2 \mathrm{a}$ provides an example of speed profiles for all recorded runs while Fig. $2 \mathrm{~b}$ presents a summary chart of recorded speed profiles. This formed the basis for the preparation of the mean speed profiles which were used to elaborate data presented in Table 2. 
a)

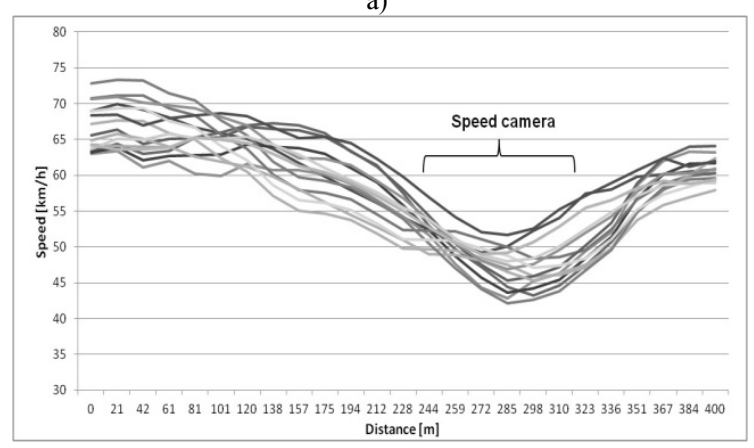

b)

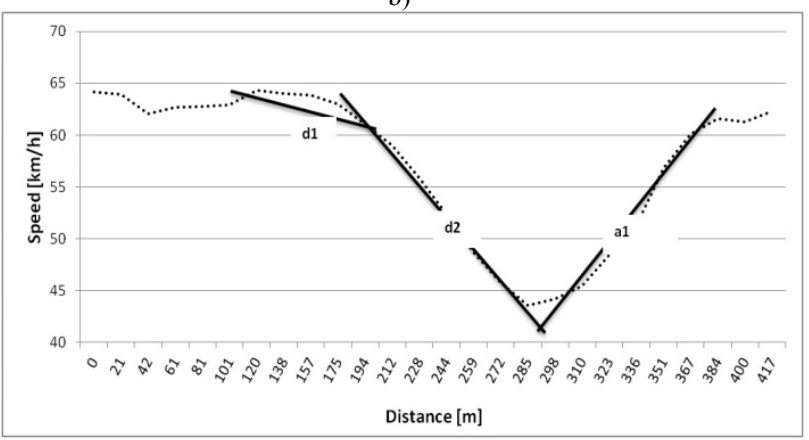

Fig. 2. Individual speed profiles around speed camera (a) summary chart and (b) average speed chart (Branickiego street)

a)

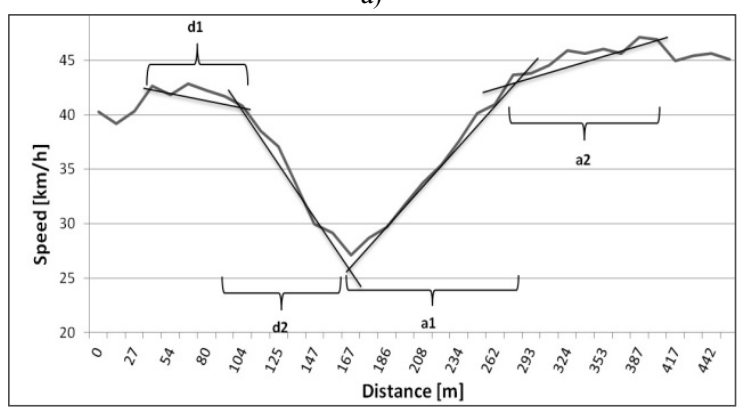

b)

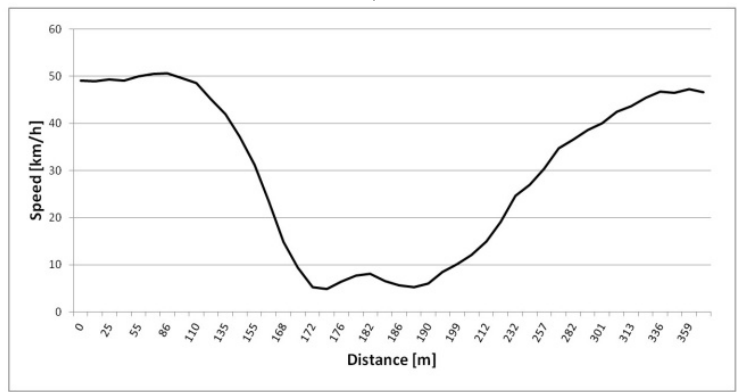

Fig. 3. Mean speed profiles for (a) speed cushions (Brzechwy street) and (b) a raised intersection (Tuwima street)

(a)

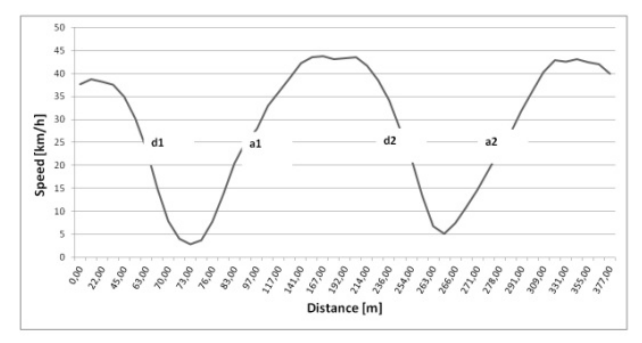

(b)

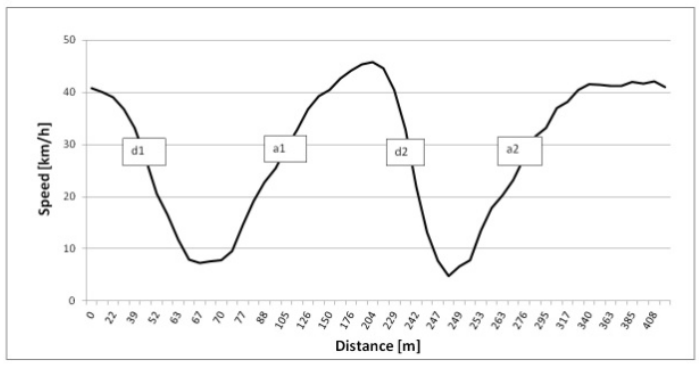

Fig. 4. Mean speed profiles for a series of (a) speed bumps (Wschodnia street) and (b) raised pedestrian crossings (Pulaskiego street)

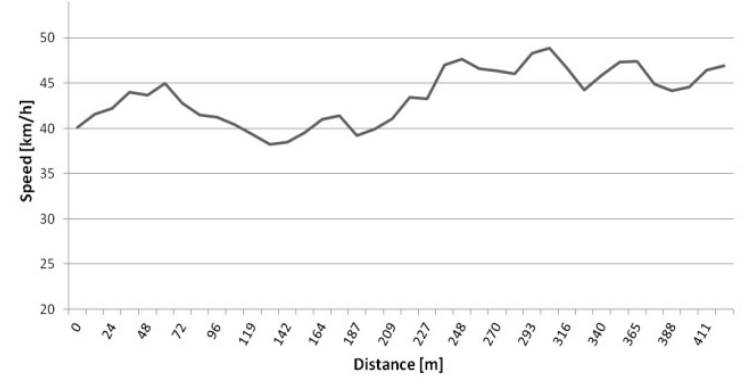

Fig. 5. Mean speed profiles for Mickiewicza street

The data provided in Table 2 reveals that a series of consecutive thresholds lead to more aggressive driving instead to enforce drivers to more fluent and non-aggressive techniques. The values of deceleration recorded before a set of speed bumps and raised pedestrian crossings are much higher (43\%-211\%) than those for single installations. Moreover deceleration processes directly before the restraint point in each case proceed more rapidly than accelerations and the slowing down is more violent in the presence of physical traffic calming measures than around speed cameras. Drivers trying to avoid slower driving on residential streets postpone the slowing down process as long as possible what entails rapid braking shortly before an obstacle which can be unexpected and dangerous for other drivers unconscious the situation 
on the road. Inappropriate spacing of TCMs may also cause aggressive driving style. Figure 4 reflects driving through consecutive slow points located $180 \mathrm{~m}$ from each other. Spacing determines the extent to which drivers speed up between slow points. If the points are located too far speeding can exceed the average speed before and after those points (Pulaskiego street) and consequently maneuvers become more rapid.

Table 2. Summary of calculated decelerations and accelerations around tested TCMs.

\begin{tabular}{lllll}
\hline \multirow{2}{*}{ Traffic calming measure } & \multicolumn{2}{l}{ deceleration $[\mathrm{m} / \mathrm{s} 2]$} & \multicolumn{2}{l}{ acceleration $[\mathrm{m} / \mathrm{s} 2]$} \\
\cline { 2 - 5 } & $\mathrm{d} 1$ & $\mathrm{~d} 2$ & $\mathrm{a} 1$ & $\mathrm{a} 2$ \\
\hline Branickiego - Speed camera & 0.32 & 0.78 & 0.71 & 0,16 \\
Brzechwy - Speed cushion & 0.28 & 0.69 & 0.70 & 0.80 \\
Tuwima - raised intersetion & 1.37 & & 0.75 & 0,86 \\
Pulaskiego - raised pedestrian crossing & 1.04 & 1.65 & 0.95 & 0,84 \\
Wschodnia - rounded speed bumps & 1.27 & 1.12 & 0.87 & \\
Kruczkowskiego - flat speed bump & 1.09 & & & \\
\hline
\end{tabular}

\section{Conclusion}

The research results confirmed that a great number of drivers do not comply with exiting traffic rules in no restraints conditions. Such behaviour enforces the search for effective solutions of speed management. Traffic calming measures are believed to be one of those and applied commonly.

When placed on a route in isolation vertical deflections such as speed humps and raised tables they occur to be the most efficient mode of reducing vehicles speeds based on point recordings. However conducted investigations have proved that when deployed independently and inappropriately their effectiveness is not satisfactory and may lead to undesirable performance. The results obtained in Pogodna street in vicinity of a single raised median island showed no influence on average speed - although the safety of pedestrian is improved the potential accident still can bring a fatal consequences.

The presence of vertical deflections along the routes resulted in drivers opting to wait to a later stage to reduce their speeds than when compared with traffic cameras. This rapid deceleration was in turn followed by a more rapid acceleration. This excessive speed in turn resulted in an even more dramatic deceleration in at the subsequent vertical controls. This tendency for individuals to drive more aggressively in the area of these types of traffic calming could in fact render them to be more dangerous in certain instances although this was not a case within tested districts.

Besides the fact that subsequent vertical installations lead to aggressive driving they are an efficient solution in preventing drivers from speed exceeding along a route. Mean speed values recorded before, after and between vertical deflections (Wschodnia and Pulaskiego streets) remained below the administrative speed limits.

The integration of a series of different speed control measures such as vertical deflections coupled with speed cameras and varied land use when forming a kind of a corridor traffic restraints gives, arguably, the best protection against speeding and aggressive driving.

\section{References}

[1] WHO. Global status report on road safety: time for action. World Health Organization, Geneva. www. who.int/violence injury prevention/road safety status/2009) 2009.

[2] Canel, A.; Nouvier, J. 2005. Road safety and automatic enforcement in France: results and outlook, Routes/Roads (1): 54-61.

[3] Ziolkowski, R. 2012. Wpływ środków uspokojenia ruchu na prędkość pojazdów w warunkach miejskich [Influence of traffic calming measures on speed in cities], Przeglad Komunikacyjny [Transport review] (4): 24-30.

[4] Gaca, S.; Jamroz, K.; Ząbczyk, K. 2004. System monitorowania zachowań kierujących pojazdami w Polsce [Monitoring system of drivers' behaviour], in VI Konferencja Bezpieczeństwa Ruchu Drogowego [VI International Conference on Traffic Safety], Zegrze 2004.

[5] Gaca, S. 2008. Zarządzanie prędkością pierwszoplanowym środkiem poprawy brd na drogach krajowych [Speed management as a main tool of safety improvement on national roads], in VII Międzynarodowe Seminarium Bezpieczeństwa Ruchu Drogowego - Gambit [VII International Seminar on Traffic Safety - Gambit], 139-147.

[6] OECD Speed Management report for the Organization for Economic Co-operation and Development, European Conference of Ministers of Transport. 20 October 2006

[7] Aljanahi, A. A. M.; Rhodes, A. H.; Metcalfe, A. V. 2001. Speed, speed limits and road traffic accidents under free flow conditions, Accident Analyses and prevention (33): 585-597.

[8] Cottrell, W. D.; Kim, N.; Martin, P. T.; Perrin, H. J. 2006. Effectiveness of traffic management in Salt Lake City, Utah, Journal of Safety Research (37): 27-41. http://dx.doi.org/10.1016/j.jsr.2005.08.007

[9] Pennsylvania Department of Transportation, 2001. Pennsylvania's Traffic Calming Handbook.

[10] Virginia Department of Transportation. 2002. Traffic calming guide for local residential streets. 